\title{
Particle Swarm Optimization Algorithm for Transportation Problems
}

\author{
Han Huang ${ }^{1}$ and Zhifeng $\mathrm{Hao}^{2}$ \\ ${ }^{1}$ School of Software Engineering, South China University of Technology \\ ${ }^{2}$ College of Mathematical Science, South China University of Technology \\ P. R. China
}

\section{Brief Introduction of PSO}

Particle swarm optimization (PSO) is a newer evolutionary computational method than genetic algorithm and evolutionary programming. PSO has some common properties of evolutionary computation like randomly searching, iteration time and so on. However, there are no crossover and mutation operators in the classical PSO. PSO simulates the social behavior of birds: Individual birds exchange information about their position, velocity and fitness, and the behavior of the flock is then influenced to increase the probability of migration to regions of high fitness. The framework of PSO can be described as Figure 1.

1. Initialize $K$ Particles $X_{1}, X_{2}, \ldots, X_{K}$, calculating pbest $_{1}, \ldots$, pbest $_{K}$ and gbest,$t=1$;

2. For $i=1, \ldots, K$ and $j=1, \ldots, N$, update particles and use $X_{i}$ to refresh pbest $_{i}$ and gbest; (shown as equation 1 and 2 )

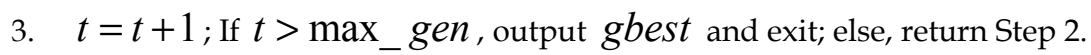

Figure 1. The framework of classical PSO

In the optimal size and shape design problem, the position of each bird is designed as variables $x$, while the velocity of each bird $v$ influences the incremental change in the position of each bird. For particle $d$ Kennedy proposed that position $x^{d}$ be updated as:

$$
\begin{gathered}
x^{d}{ }_{t+1}=x^{d}{ }_{t}+v^{d}{ }_{t+1} \\
v^{d}{ }_{t+1}=v^{d}{ }_{t}+c_{1} r_{1}\left(p^{d}{ }_{t}-x^{d}{ }_{t}\right)+c_{2} r_{2}\left(p^{g}{ }_{t}-x^{d}{ }_{t}\right)
\end{gathered}
$$

Here, $p^{d}{ }_{t}$ is the best previous position of particle $d$ at time $t$, while $p^{g}{ }_{t}$ is the global best position in the swarm at timet. $r_{1}$ and $r_{2}$ are uniform random numbers between 0 and 1 , and $c_{1}=c_{2}=2$. 


\section{Particle Swarm Optimization for linear Transportation Problem}

\subsection{Linear and Balance Transportation Problem}

The transportation problem (TP) is one of the fundamental problems of network flow optimization. A surprisingly large number of real-life applications can be formulated as a TP. It seeks determination of a minimum cost transportation plan for a single commodity from a number of sources to a number of destinations. So the LTP can be described as: Given there are $n$ sources and $m$ destinations. The amount of supply at source $i$ is $a_{i}$ and the demand at destination $j$ is $b_{j}$. The unit transportation cost between source $i$ and destination $j$ is $c_{i j} . x_{i j}$ is the transport amount from source $i$ to destination $j$, and the LTP model is:

$$
\begin{gathered}
\min \quad z=\sum_{i=1}^{n} \sum_{j=1}^{m} c_{i j} x_{i j} \\
\text { s.t. } \sum_{j=1}^{m} x_{i j} \leq a_{i} \quad i=1,2, \ldots, n \\
\sum_{i=1}^{n} x_{i j} \geq b_{j} \quad j=1,2, \ldots, m . \\
x_{i j} \geq 0 ; \quad i=1,2, \ldots, n ; j=1,2, \ldots, m
\end{gathered}
$$

TP has been paid much attention to and classified into several types of transmutation. According to the nature of object function, there are four types: (1) linear TP and nonlinear TP. (2) single objective TP and multi objective. Based on the type of constraints, there are planar TP and solid TP. The single object LTP dealt with in this paper is the basic model for other kinds of transportation problems.

A special LTP called balanced LTP is considered as follows:

$$
\begin{gathered}
\min z=\sum_{i=1}^{n} \sum_{j=1}^{m} c_{i j} x_{i j} \\
\text { s.t. } \quad \sum_{j=1}^{m} x_{i j}=a_{i} \quad i=1,2, \ldots, n \\
\sum_{i=1}^{n} x_{i j}=b_{j} \quad j=1,2, \ldots, m . \\
\sum_{i=1}^{n} a_{i}=\sum_{j=1}^{m} b_{j} \\
i=1,2, \ldots, n ; j=1,2, \ldots, m
\end{gathered}
$$


The fact that a $n \times m$ LTP can be changed into a $n \times(m+1)$ balanced LTP, can be found in operational research because the demand at destination $m+1$ could be calculated by $b_{m+1}=\sum_{i=1}^{n} a_{i}-\sum_{j=1}^{m} b_{j}$ with the condition $\sum_{i=1}^{n} a_{i} \geq \sum_{j=1}^{m} b_{j}$.

\subsection{Initialization of PSO for Linear and Balance Particle Swarm Optimization}

A particle $X=\left[\begin{array}{ccc}x_{11} & \ldots & x_{1 m} \\ \ldots & \ldots & \ldots \\ x_{n 1} & \ldots & x_{n m}\end{array}\right]$ stands for a solution to LTP. There are $n m$ particles

initialized to form $\mathrm{nm}$ initial solutions in the initialization. Every element of set $N$ can be chosen as the first assignment to generate the solutions dispersedly, which is good for obtaining the optimal solution in the iteration.

If a LTP is balanced, the following procedure can be used to obtain an initial solution:

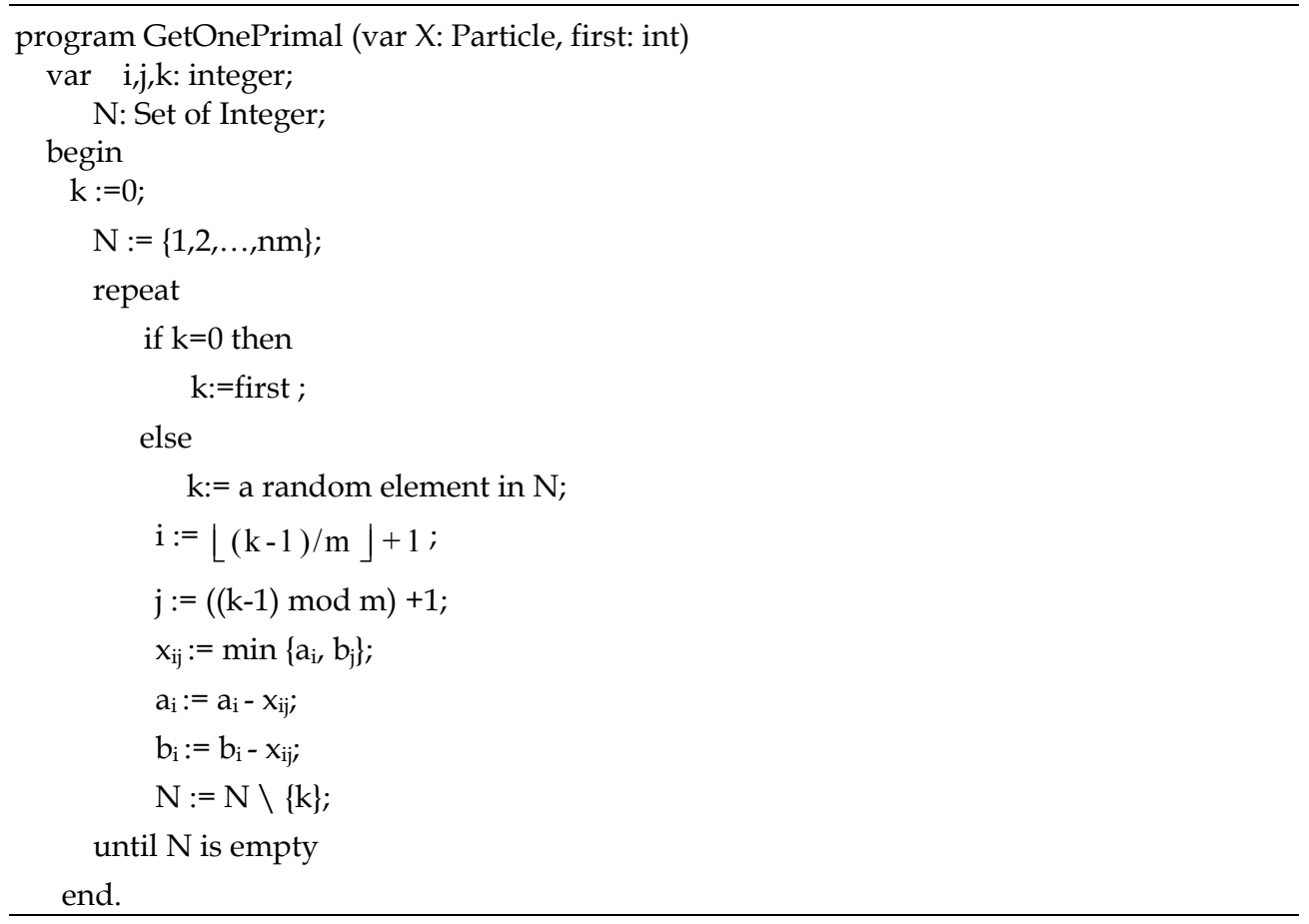


And the initialization of PSO-TP can be designed as follows:

program Initialization

var i : integer;

begin

Get a balanced LTP;

i : $:=1$;

repeat

GetOnePrimal $\left(X_{i}, i\right)$;

$\mathrm{i}:=\mathrm{i}+1$;

until i > nm

end.

\subsection{Updating Rule of PSO for Linear and Balance Particle Swarm Optimization}

In PSO algorithm, a new solution can be obtained by using the position updating rule as equations 2 and 3 . However, the classical rule is unable to meet such constraints of TP as $\sum_{j=1}^{m} x_{i j}=a_{i}$ and $\sum_{i=1}^{n} x_{i j}=b_{j}$. A new rule is designed to overcome this shortcoming. For particle $d$, we propose that position $X^{d}(n \times m)$ be updated as

$$
V_{t+1}^{d}=\left\{\begin{array}{cr}
\varphi_{1}\left(P_{t}^{d}-X_{t}^{d}\right)+\varphi_{2}\left(P_{t}^{g}{ }_{t}-X_{t}^{d}\right) & t=0 \\
\lambda_{1} V_{t}^{d}+\lambda_{2}\left[\varphi_{1}\left(P_{t}^{d}{ }_{t}-X^{d}{ }_{t}\right)+\varphi_{2}\left(P_{t}^{g}-X_{t}^{d}\right)\right] & t>0 \\
X_{t+1}^{d}=V_{t+1}^{d}+X_{t}^{d} &
\end{array}\right.
$$

where $P_{t}^{g} \neq X_{t}^{d}$ and $P_{t}^{d} \neq X_{t}^{d}$.

If $P_{t}^{g}=X_{t}^{d}$ and $P_{t}^{d} \neq X_{t}^{d}, \varphi_{1}=1$. If $P_{t}^{g} \neq X_{t}^{d}$ and $P_{t}^{d}=X_{t}^{d}, \varphi_{2}=1$. If $P_{t}^{g}=X_{t}^{d}$ and $P_{t}^{d}=X_{t}^{d}, \lambda_{1}=1$.

$P^{d}{ }_{t}(n \times m)$ is the best previous position of particle $d$ at time $t$, while $P^{g}{ }_{t}(n \times m)$ is the global best position in the swarm at time $t . \varphi_{1}$ and $\varphi_{2}$ are uniform random numbers in $(0$, 1), meeting $\varphi_{1}+\varphi_{2}=1$, while $\lambda_{1}$ is a uniform random number between $[0.8,1.0)$ and $\lambda_{2}=1-\lambda_{1}$.

$$
\begin{gathered}
\text { if } t=0, X^{d}{ }_{t+1}=V^{d}{ }_{t+1}+X^{d}{ }_{t} \\
=\varphi_{1}\left(P^{d}{ }_{t}-X^{d}{ }_{t}\right)+\varphi_{2}\left(P_{t}^{g}{ }_{t}-X^{d}{ }_{t}\right)+X^{d}{ }_{t}=\left(\varphi_{1} P^{d}{ }_{t}+\varphi_{2} P_{t}^{g}{ }_{t}\right)-\left(\varphi_{1} X_{t}^{d}+\varphi_{2} X^{d}{ }_{t}\right)+X^{d}{ }_{t}
\end{gathered}
$$




$$
\begin{aligned}
& \sum_{j=1}^{m} x_{i j}^{d}(t+1) \\
& =\varphi_{1} \sum_{j=1}^{m} p_{i j}^{d}(t)+\varphi_{2} \sum_{j=1}^{m} p_{i j}^{g}(t)-\left(\varphi_{1} \sum_{j=1}^{m} x_{i j}^{d}(t)+\varphi_{2} \sum_{j=1}^{m} x_{i j}^{d}(t)\right)+\sum_{j=1}^{m} x_{i j}^{d}(t) \\
& =\varphi_{1} a_{i}+\varphi_{2} a_{i}-\left(\varphi_{1} a_{i}+\varphi_{2} a_{i}\right)+a_{i}=a_{i} \\
& \sum_{i=1}^{n} x_{i j}^{d}(t+1) \\
& =\varphi_{1} \sum_{i=1}^{n} p_{i j}^{d}(t)+\varphi_{2} \sum_{i=1}^{n} p_{i j}^{g}(t)-\left(\varphi_{1} \sum_{i=1}^{n} x_{i j}^{d}(t)+\varphi_{2} \sum_{i=1}^{n} x_{i j}^{d}(t)\right)+\sum_{i=1}^{n} x_{i j}^{d}(t) \\
& =\varphi_{1} b_{j}+\varphi_{2} b_{j}-\left(\varphi_{1} b_{j}+\varphi_{2} b_{j}\right)+b_{j}=b_{j} \\
& \text { if } t>0 \text {, } \\
& X_{t+1}^{d}=V_{t+1}^{d}+X_{t}^{d} \\
& =\lambda_{1} V_{t}^{d}+\lambda_{2}\left[\varphi_{1}\left(P_{t}^{d}-X_{t}^{d}\right)+\varphi_{2}\left(P_{t}^{g}-X_{t}^{d}\right)\right]+X_{t}^{d} \\
& =\lambda_{1} V_{t}^{d}+\lambda_{2}\left[\left(\varphi_{1} P_{t}^{d}+\varphi_{2} P_{t}^{g}\right)-\left(\varphi_{1} X_{t}^{d}+\varphi_{2} X^{d}{ }_{t}\right)\right]+X^{d}{ }_{t} \\
& =\lambda_{1}\left(X^{d}{ }_{t}-X^{d}{ }_{t-1}\right)+\lambda_{2}\left[\left(\varphi_{1} P^{d}{ }_{t}+\varphi_{2} P_{t}^{g}\right)-\left(\varphi_{1} X^{d}{ }_{t}+\varphi_{2} X^{d}{ }_{t}\right)\right]+X^{d}{ }_{t} \\
& \sum_{j=1}^{m} x_{i j}^{d}(t+1)=\lambda_{1}\left(\sum_{j=1}^{m} x_{i j}^{d}(t)-\sum_{j=1}^{m} x_{i j}^{d}(t-1)\right)+\lambda_{2}\left(\varphi_{1} a_{i}+\varphi_{2} a_{i}-\left(\varphi_{1} a_{i}+\varphi_{2} a_{i}\right)\right)+a_{i} \\
& =\lambda_{1}\left(a_{i}-a_{i}\right)+0+a_{i}=a_{i} \\
& \sum_{i=1}^{n} x_{i j}^{d}(t+1) \\
& =\lambda_{1}\left(\sum_{i=1}^{n} x_{i j}^{d}(t)-\sum_{i=1}^{n} x_{i j}^{d}(t-1)\right)+\lambda_{2}\left(\varphi_{1} b_{j}+\varphi_{2} b_{j}-\left(\varphi_{1} b_{j}+\varphi_{2} b_{j}\right)\right)+b_{j} \\
& =\lambda_{1}\left(b_{j}-b_{j}\right)+0+b_{j}=b_{j}
\end{aligned}
$$


Therefore, $X_{t+1}^{d}$ would meet the condition that $\sum_{j=1}^{m} x_{i j}^{d}(t+1)=a_{i}$ and $\sum_{i=1}^{n} x_{i j}^{d}(t+1)=b_{j}$ with the function of Formulae 5 and 6 . However, the new rule cannot ensure the last constraint that $x_{i j} \geq 0, i=1, . ., n, j=1, \ldots, m$. In the following section, an extra operator is given to improve the algorithm.

\subsection{Negative Repair Operator}

A particle of PSO-TP (Formula 7) will be influenced by the negative repair operator if $x_{k i}<0, k=1, \ldots, n, i=1, \ldots, m$, which is indicated as follows:

$$
X=\left[\begin{array}{ccccc}
x_{11} & \ldots & x_{1 i} & \ldots & x_{1 m} \\
\ldots & \ldots & \ldots & \ldots & \ldots \\
x_{k 1} & \ldots & x_{k i} & \ldots & x_{k m} \\
\ldots & \ldots & \ldots & \ldots & \ldots \\
x_{l 1} & \ldots & x_{l i} & \ldots & x_{l m} \\
\ldots & \ldots & \ldots & \ldots & \ldots \\
x_{n 1} & \ldots & x_{n i} & \ldots & x_{n m}
\end{array}\right]
$$

program RepairOnePos (var X: Particle, k,i: int)

begin

select the maximum element signed as $x_{l i}$ in Col. i;

$$
x_{0}:=x_{k i}, x_{l i}:=x_{l i}-\left|x_{0}\right|, x_{k i}:=0
$$

change elements in Row.k into $x_{k j}:=\left\{\begin{array}{cc}x_{k j} & x_{k j}=0 \\ x_{k j}-\frac{\left|x_{0}\right|}{u} & x_{k j}>0\end{array} ;\right.$

( $u$ is the number of times when the following condition $x_{k j}>0, j=1, \ldots, m$ is met)

$$
\text { change elements in Row. } 1 \text { into } x_{l j}:=\left\{\begin{array}{cc}
x_{l j} & x_{k j}=0 \\
x_{l j}+\frac{\left|x_{0}\right|}{u} & x_{k j}>0
\end{array} ;\right.
$$

end. 
As a result, the procedure of negative repair operator can be described as:

program NegativeRepair (var X: Particle)

var i,j: integer;

begin

if some element of $X$ is negative then

repeat

If $\mathrm{x}_{\mathrm{ij}}<0$ is found then

RepairOnePos $(X, \mathrm{i}, \mathrm{j})$;

until Every element of $X$ is not negative

end.

\subsection{PSO Mutation}

Mutation is a popular operator in Genetic Algorithm, and a special PSO mutation is designed to help PSO-TP change the partial structure of some particles in order to get new types of solution. PSO-TP cannot fall into the local convergence easily because the mutation operator can explore the new solution.

program PSOMutation (var X: Particle)

begin

Obtain $\mathrm{p}$ and $\mathrm{q}$ randomly meeting $0<\mathrm{p}<\mathrm{n}$ and $0<\mathrm{q}<\mathrm{m}$;

Select $p$ rows $\left\{i_{1}, \ldots i_{p}\right\}$ and $q$ lines $\left\{j_{1}, \ldots j_{q}\right\}$ randomly from matrix $X$ to form a small matrix $\mathrm{Y}\left(\mathrm{y}_{\mathrm{ij}, \mathrm{i}} \mathrm{i}=1, \ldots, \mathrm{p}, \mathrm{j}=1, \ldots, \mathrm{q}\right)$;

$$
\begin{aligned}
& a^{y}{ }_{i}=\sum_{j \in\left\{j_{1}, \ldots, j_{q}\right\}} x_{i j} \quad\left(i=i_{1}, \ldots, i_{p}\right) \\
& b^{y}{ }_{j}=\sum_{i \in\left\{i_{1}, \ldots, i_{p}\right\}} x_{i j} \quad\left(j=j_{1}, \ldots, j_{q}\right)
\end{aligned}
$$

Use a method like the one in initialization to form the initial assignment for $Y$;

Update X with Y;

end.

\subsection{The Structure of PSO-TP}

According to the setting above, the structure of PSO-TP is shown as:

program PSO-TP (problem: balanced LTP of $n \times m$ size, pm: float)

var t:integer;

begin

$\mathrm{t}:=0$;

Initialization; 
Obtain $P_{0}(n \times m)$ and $P_{0}^{d}(n \times m)(\mathrm{d}=1, \ldots, \mathrm{n} \times \mathrm{m}) ;$

repeat

$\mathrm{t}:=\mathrm{t}+1$

Calculate $X^{d}{ }_{t}$ with Formula 5 and $6(\mathrm{~d}=1, \ldots, \mathrm{n} \times \mathrm{m}) ;$

NegativeRepair $\left(X_{t}^{d}\right)(\mathrm{d}=1, \ldots, \mathrm{n} \times \mathrm{m})$;

Carry out PSOMutation $\left(X^{d}{ }_{t}\right)$ by the probability pm;

Update $P_{t}^{g}(n \times m)$ and $P^{d}{ }_{t}(n \times m)(\mathrm{d}=1, \ldots, \mathrm{n} \times \mathrm{m}) ;$

until meeting the condition to stop

end.

\section{Numerical Results}

There are two experiments in this section: one is comparing PSO-TP with genetic algorithm (GA) in some integer instances and the second is testing the performance of PSO-TP in the open problems. Both of the experiments are done at a PC with 3.06G Hz, 512M DDR memory and Windows XP operating system. GA and PSO-TP would stop when no better solution could be found in 500 iterations, which is considered as a virtual convergence of the algorithms. The probability of mutation in PSO-TP is set to be 0.05 .

\begin{tabular}{|l|l|l|l|l|l|l|}
\hline $\begin{array}{l}\text { Problem } \\
\text { five runs }\end{array}$ & $\begin{array}{l}\text { PSO-TP } \\
\text { Min }\end{array}$ & $\begin{array}{l}\text { PSO-TP } \\
\text { Ave }\end{array}$ & $\begin{array}{l}\text { GA } \\
\text { Min }\end{array}$ & $\begin{array}{l}\text { GA } \\
\text { Ave }\end{array}$ & $\begin{array}{l}\text { PSO-TP } \\
\text { Time(s) }\end{array}$ & $\begin{array}{l}\text { GA } \\
\text { Time(s) }\end{array}$ \\
\hline P1 $\left(3^{*} 4\right)$ & 152 & 152 & 152 & 153 & 0.015 & 1.72 \\
\hline P2 $\left(4^{*} 8\right)$ & 287 & 288 & 290 & 301 & 0.368 & 5.831 \\
\hline P3 $\left(3^{*} 4\right)$ & 375 & 375 & 375 & 375 & 0.028 & 0.265 \\
\hline P4 $\left(3^{*} 4\right)$ & 119 & 119 & 119 & 119 & 0.018 & 1.273 \\
\hline P5 $\left(3^{*} 4\right)$ & 85 & 85 & 85 & 85 & 0.159 & 0.968 \\
\hline P6*(15*20) & 596 & 598 & - & - & 36.4 & - \\
\hline
\end{tabular}

Table 1. Comparison Between PSO-TP and GA

As Table 1 shows, both the minimum cost and average cost obtained by PSO-TP are less than those of GA. Furthermore, the time cost of PSO-TP is much less than that of GA. In order to verify the effectiveness of PSO-TP, 9 real number instances are computed and the results are shown in Table 2. Since GA is unable to deal with the real number LTP directly, only PSO-T is tested. 


\begin{tabular}{|l|l|l|l|}
\hline Problem \five runs & Optimal Value & PSO-TP Average & PSO-TP Time(s) \\
\hline No.1 & 67.98 & 67.98 & 0.02 \\
\hline No.2 & 1020 & 1020 & 0.184 \\
\hline No.4 & 13610 & 13610 & 0.168 \\
\hline No.5 & 1580 & 1580 & 0.015 \\
\hline No.6 & 98 & 98 & 0.023 \\
\hline No.7 & 2000 & 2000 & 0.015 \\
\hline No.8 & 250 & 250 & $<0.001$ \\
\hline No.9 & 215 & 215 & 0.003 \\
\hline No.10 & 110 & 110 & 0.012 \\
\hline
\end{tabular}

Table 2. Performance of PSO-TP in open problems

According to the results in Table 2, PSO-TP can solve the test problems very quickly. The efficiency of PSO-TP may be due to the characteristic of PSO algorithm and the special operators. Through the function of the new position updating rule and negative repair operator, the idea of PSO is introduced to solve LTP successfully. The nature of PSO can accelerate the searching of the novel algorithm, which would also enable PSO-TP to get the local best solution. What's more, the PSO mutation as an extra operator can help PSO-TP to avoid finishing searching prematurely. Therefore, PSO-TP can be a novel effective algorithm for solving TP.

\section{Particle Swarm Optimization for Non-linear Transportation Problem}

\subsection{Non-linear and Balance Transportation Problem}

The unit transportation cost between source $i$ and destination $j$ is $f_{i j}\left(x_{i j}\right)$ where $x_{i j}$ is the transportation amount from source $i$ to destination $j$, and TP model is:

$$
\begin{gathered}
\min \quad z=\sum_{i=1}^{n} \sum_{j=1}^{m} f_{i j}\left(x_{i j}\right) \\
\text { s.t. } \sum_{j=1}^{m} x_{i j} \leq a_{i} \quad i=1,2, \ldots, n \\
\sum_{i=1}^{n} x_{i j} \geq b_{j} \quad j=1,2, \ldots, m . \\
x_{i j} \geq 0 ; \quad i=1,2, \ldots, n ; j=1,2, \ldots, m
\end{gathered}
$$


According to the nature of object function, there are four types: linear TP in which the function $f_{i j}\left(x_{i j}\right)$ is linear and nonlinear TP in which $f_{i j}\left(x_{i j}\right)$ is non-linear, as well as single objective and multi-objective TP. Based on the types of constraints, there are planar TP and solid TP. The single object NLTP is dealt with in this paper. In many fields like railway transportation, the relation between transportation amount and price is often nonlinear, so NLTP is an important for application.

\subsection{Framework of PSO for Non-linear TP}

In the population of PSO-NLTP, an individual $X_{i}=\left[\begin{array}{ccc}x_{11} & \ldots & x_{1 m} \\ \ldots & \ldots & \ldots \\ x_{n 1} & \ldots & x_{n m}\end{array}\right]$ stands for a solution to NLTP (Exp. 2), where $n \times m$ is the population size. There are $n \times m$ individuals initialized to form $n \times m$ initial solutions in the initialization. The initialization and mutation are the same as the ones in PSO-LTP (Section 2.2 and 2.5).

And the framework of PSO-NLTP is given:

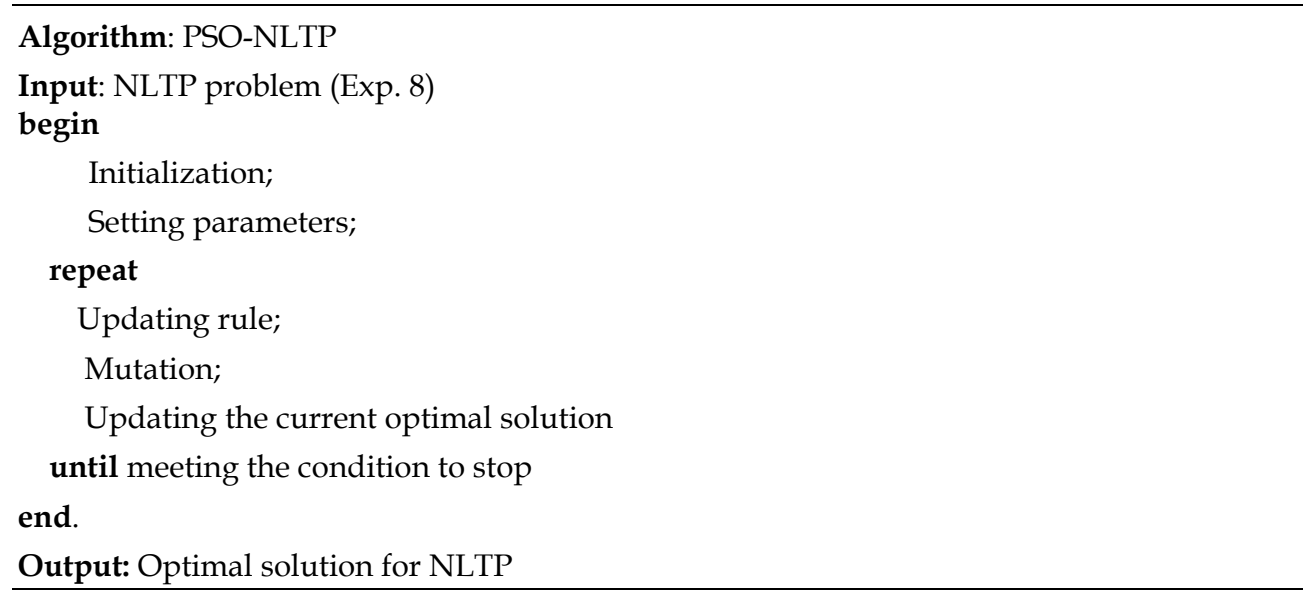

In the parameter setting, The parameters of PSO-NLTP are all set adaptively: as the population size is $n \times m$, the size of mutation matrix $\mathrm{Y}$ is set randomly meeting $0<\mathrm{p}<\mathrm{n}$ and $0<\mathrm{q}<\mathrm{m}$ and the mutation probability $P_{m}$ is calculated by $P_{m}=0.005 \times N_{t}$, where $N_{t}=1$ when $X_{\text {best }}{ }^{(t)}$ is updated and $N_{t}=N_{t}+1$ when $X_{\text {best }}{ }^{(t)}$ remains the same as $X_{\text {best }}{ }^{(t-1)}$.

\subsection{Updating Rule of PSO-NLTP}

As one of the important evolutionary operator, recombination is designed to optimize the individuals and make them meet the constraints of supply and demand as $\sum_{j=1}^{m} x_{i j}=a_{i}$ and 
$\sum_{i=1}^{n} x_{i j}=b_{j}$ (Exp. 4). At the beginning of an iteration, every individual is recombined by the following expression.

$$
X_{i}^{(t+1)}=\varphi_{1} X_{i}^{(t)}+\varphi_{2} X_{\text {best }}^{(t)}+\varphi_{3} X_{\text {random }}{ }^{(t)}
$$

$X_{\text {best }}{ }^{(t)}$ is the best particle found by PSO-NLTP form iteration 0 to $t . X_{\text {random }}{ }^{(t)}$ is the particle formed randomly (by sub-algorithm GetOnePrimal in section 2.2) for the updating rule of $X_{i}^{(t)} \cdot \varphi_{1}, \varphi_{2}$ and $\varphi_{3}$ are the weight terms meeting $\varphi_{1}+\varphi_{2}+\varphi_{3}=1$, which are calculated as Exp 4-6 show, where $f\left(X_{i}{ }^{(t)}\right)$ is the cost of the solution for TP (Exp. 4).

$$
\begin{gathered}
\varphi_{1}=f\left(X_{i}^{(t)}\right)^{-1} /\left(f\left(X_{i}^{(t)}\right)^{-1}+f\left(X_{\text {best }}{ }^{(t)}\right)^{-1}+f\left(X_{\text {random }}{ }^{(t)}\right)^{-1}\right) \\
\varphi_{2}=f\left(X_{\text {best }}{ }^{(t)}\right)^{-1} /\left(f\left(X_{i}^{(t)}\right)^{-1}+f\left(X_{\text {best }}{ }^{(t)}\right)^{-1}+f\left(X_{\text {random }}{ }^{(t)}\right)^{-1}\right) \\
\varphi_{3}=f\left(X_{\text {random }}{ }^{(t)}\right)^{-1} /\left(f\left(X_{i}^{(t)}\right)^{-1}+f\left(X_{\text {best }}{ }^{(t)}\right)^{-1}+f\left(X_{\text {random }}{ }^{(t)}\right)^{-1}\right)
\end{gathered}
$$

$X_{i}^{(t+1)}$ can be considered as a combination of $X_{i}^{(t)}, X_{\text {best }}{ }^{(t)}$ and $X_{\text {random }}{ }^{(t)}$ based on the their quality, and proved to meet the constraints of supply and demand.

$$
\begin{aligned}
& \sum_{j=1}^{m} x_{i j}{ }^{(t+1)}=\sum_{j=1}^{m}\left(\varphi_{1} x_{i j}{ }^{(t)}+\varphi_{2} x_{i, j, \text { best }}{ }^{(t)}+\varphi_{3} x_{i, j, \text { random }}{ }^{(t)}\right) \\
& =\varphi_{1} \sum_{j=1}^{m} x_{i j}{ }^{(t)}+\varphi_{2} \sum_{j=1}^{m} x_{i, j, \text { best }}{ }^{(t)}+\varphi_{3} \sum_{j=1}^{m} x_{i, j, \text { random }}{ }^{(t)} \\
& =\varphi_{1} a_{i}+\varphi_{2} a_{i}+\varphi_{3} a_{i}=a_{i} \quad(i=1, \ldots, n) \\
& \sum_{i=1}^{n} x_{i j}{ }^{(t+1)}=\sum_{i=1}^{n}\left(\varphi_{1} x_{i j}{ }^{(t)}+\varphi_{2} x_{i, j, \text { best }}{ }^{(t)}+\varphi_{3} x_{i, j, \text { random }}{ }^{(t)}\right) \\
& =\varphi_{1} \sum_{i=1}^{n} x_{i j}{ }^{(t)}+\varphi_{2} \sum_{i=1}^{n} x_{i, j, \text { best }}{ }^{(t)}+\varphi_{3} \sum_{i=1}^{n} x_{i, j, \text { random }}{ }^{(t)} \\
& =\varphi_{1} b_{j}+\varphi_{2} b_{j}+\varphi_{3} b_{j}=b_{j} \quad(j=1, \ldots, m)
\end{aligned}
$$


Furthermore, the recombination rule can also ensure the positive constraint that

$$
x_{i j}{ }^{(t+1)}=\varphi_{1} x_{i j}{ }^{(t)}+\varphi_{2} x_{i, j, \text { best }}{ }^{(t)}+\varphi_{3} x_{i, j, \text { random }}{ }^{(t)} \geq 0, i=1, \ldots, n, j=1, \ldots, m \text {. }
$$

\subsection{Numerical Results}

There are 56 NLTP instances computed in the experiment, of which the results are shown in this section. The experiment is done at a PC with $3.06 \mathrm{G} \mathrm{Hz}, 512 \mathrm{M}$ DDR memory and Windows XP operating system. The NLTP instances are generated by replacing the linear cost functions of the open problems with the non-linear functions. The methods which are effective for linear TP cannot deal with NLTP for the complexity of non-linear object function. The common NLTP cost functions are indicated in Table 1.

\begin{tabular}{|l|l|}
\hline Problem & Transportation Cost Functions \\
\hline No.1 & $f_{i j}\left(x_{i j}\right)=c_{i j} x_{i j}^{2}$ \\
\hline No.2 & $f_{i j}\left(x_{i j}\right)=c_{i j} \sqrt{x_{i j}}$ \\
\hline No.3 & $f_{i j}\left(x_{i j}\right)=\left\{\begin{array}{l}c_{i j}\left(\frac{x_{i j}}{S}\right), \quad \text { if } 0 \leq x_{i j}<S \\
c_{i j}, \quad i f \quad S<x_{i j} \leq 2 S \\
c_{i j}\left(1+\frac{x_{i j}-2 S}{S}\right), \text { if } 2 S<x_{i j}\end{array}\right.$ \\
\hline No.4 & $f_{i j}\left(x_{i j}\right)=c_{i j} x_{i j}\left[\sin \left(x_{i j} \frac{5 \pi}{4 S}\right)+1\right]$ \\
\hline
\end{tabular}

Table 3. NLTP cost functions [15]

The comparison between PSO-NLTP and EP with penalty strategy only indicates whether the recombination of PSO-NLTP is better at dealing with the constraints of NLTP (Exp. 8) than penalty strategy of EP. There cannot be any conclusion that PSO-NLTP or EP is better than the other because they are the algorithms for different applications. The three algorithms are computed in 50 runs independently, and the results are in Table 4 and Table 5. They would stop when no better solution could be found in 100 iterations, which is considered as a virtual convergence of the algorithms.

NLTP instances in Table 4 are formed with the non-linear functions (shown in Table 3) and the problems. And the instances in Table 5 are formed with the non-linear functions and the problems. We set $S=\sum_{i=1}^{n} a_{i} / 10$ in function No.3 and $S=1$ in function No.4 in the experiment. 


\begin{tabular}{|c|c|c|c|c|c|c|}
\hline Problem & $\begin{array}{l}\text { PSO-NLTP } \\
\text { Average }\end{array}$ & $\begin{array}{l}\text { GA } \\
\text { Average }\end{array}$ & $\begin{array}{l}\text { EP } \\
\text { Average }\end{array}$ & $\begin{array}{l}\text { PSO-NLTP } \\
\text { Time(s) }\end{array}$ & $\begin{array}{l}\text { GA } \\
\text { Time(s) }\end{array}$ & $\begin{array}{l}\text { EP } \\
\text { Time(s) }\end{array}$ \\
\hline No.1-1 & 8.03 & 8.10 & 8.36 & 0.093 & 0.89 & 0.109 \\
\hline No.1-2 & 112.29 & 114.25 & 120.61 & 0.11 & 0.312 & 0.125 \\
\hline No.1-4 & 1348.3 & 1350.8 & 1476.1 & 0.062 & 0.109 & 0.078 \\
\hline No.1-5 & 205.9 & 206.3 & 216.1 & 0.043 & 0.125 & 0.052 \\
\hline No.1-6 & 12.64 & 12.72 & 13.53 & 0.062 & 0.75 & 0.078 \\
\hline No.1-7 & 246.9 & 247.6 & 256.9 & 0.088 & 0.32 & 0.093 \\
\hline No.1-8 & 84.72 & 84.72 & 87.5 & $<0.001$ & 0.015 & $<0.001$ \\
\hline No.1-9 & 44.64 & 44.65 & 46.2 & $<0.001$ & 0.046 & $<0.001$ \\
\hline No.1-10 & 24.85 & 24.97 & 25.83 & $<0.001$ & 0.032 & $<0.001$ \\
\hline No.2-1 & 155.3 & 155.3 & 168.5 & $<0.001$ & 0.016 & $<0.001$ \\
\hline No.2-2 & 2281.5 & 2281.5 & 2696.2 & $<0.001$ & 0.015 & $<0.001$ \\
\hline No.2-4 & 28021 & 28021 & 30020.2 & $<0.001$ & 0.015 & $<0.001$ \\
\hline No.2-5 & 3519.3 & 3520.4 & 3583.1 & $<0.001$ & 0.015 & $<0.001$ \\
\hline No.2-6 & 264.9 & 266.5 & 314.4 & $<0.001$ & 0.015 & $<0.001$ \\
\hline No.2-7 & 4576.9 & 4584.5 & 5326.0 & 0.009 & 0.052 & 0.012 \\
\hline No.2-8 & 432.8 & 432.8 & 432.8 & $<0.001$ & 0.015 & $<0.001$ \\
\hline No.2-9 & 386.3 & 386.3 & 386.3 & $<0.001$ & 0.031 & $<0.001$ \\
\hline No.2-10 & 195.3 & 195.3 & 226.0 & $<0.001$ & 0.006 & $<0.001$ \\
\hline No.3-1 & 309.9 & 310.0 & 346.6 & $<0.001$ & 0.093 & 0.001 \\
\hline No.3-2 & 4649.2 & 4650 & 5415.2 & $<0.001$ & 0.921 & 0.012 \\
\hline No.3-4 & 65496.7 & 66123.3 & 68223.3 & $<0.001$ & 0.105 & $<0.001$ \\
\hline No.3-5 & 7038.1 & 7066.6 & 7220.9 & $<0.001$ & 1.015 & 0.001 \\
\hline No.3-6 & 540 & 540 & 672.5 & 0.001 & 0.062 & 0.002 \\
\hline No.3-7 & 9171.0 & 9173.2 & 9833.3 & $<0.001$ & 0.312 & $<0.001$ \\
\hline No.3-8 & 1033.4 & 1033.4 & 1066.7 & $<0.001$ & 0.012 & $<0.001$ \\
\hline No.3-9 & 933.3 & 933.4 & 1006.4 & 0.002 & 0.147 & 0.015 \\
\hline No.3-10 & 480 & 480 & 480 & 0.016 & 0.046 & 0.004 \\
\hline No.4-1 & 107.6 & 107.8 & 118.2 & 0.063 & 0.159 & 0.078 \\
\hline No.4-2 & 1583.5 & 1585.2 & 1622 & 0.062 & 0.285 & 0.093 \\
\hline No.4-4 & 19528.4 & 19531.3 & 20119 & 0.075 & 0.968 & 0.068 \\
\hline No.4-5 & 2466.9 & 2468.2 & 2880.2 & 0.072 & 0.625 & 0.046 \\
\hline No.4-6 & 151.7 & 152.1 & 161.9 & 0.093 & 1.046 & 0.167 \\
\hline No.4-7 & 3171.1 & 3173.8 & 3227.5 & 0.047 & 0.692 & 0.073 \\
\hline No.4-8 & 467.1 & 467.1 & 467.1 & $<0.001$ & 0.036 & $<0.001$ \\
\hline No.4-9 & 376.3 & 376.3 & 382.5 & $<0.001$ & 0.081 & 0.003 \\
\hline No.4-10 & 205.9 & 205.9 & 227.6 & 0.026 & 0.422 & 0.031 \\
\hline
\end{tabular}

Table 4. Comparison I between PSO-NLTP, GA and EP with penalty strategy 


\begin{tabular}{|l|l|l|l|l|l|l|}
\hline Problem & $\begin{array}{l}\text { PSO-NLTP } \\
\text { Average }\end{array}$ & $\begin{array}{l}\text { GA } \\
\text { Average }\end{array}$ & $\begin{array}{l}\text { EP } \\
\text { Average }\end{array}$ & $\begin{array}{l}\text { PSO-NLTP } \\
\text { Time(s) }\end{array}$ & $\begin{array}{l}\text { GA } \\
\text { Time(s) }\end{array}$ & $\begin{array}{l}\text { EP } \\
\text { Time(s) }\end{array}$ \\
\hline No.1-11 & 1113.4 & 1143.09 & 1158.2 & 0.031 & 0.065 & 0.046 \\
\hline No.1-12 & 429.3 & 440.3 & 488.3 & 0.187 & 1.312 & 0.203 \\
\hline No.1-13 & 740.5 & 740.5 & 863.6 & 0.09 & 2.406 & 0.781 \\
\hline No.1-14 & 2519.4 & 2529.0 & 2630.3 & 0.015 & 0.067 & 0.016 \\
\hline No.1-15 & 297.2 & 297.9 & 309.2 & 0.046 & 0.178 & 0.058 \\
\hline No.1-16 & 219.92 & 220.8 & 234.6 & 0.040 & 1.75 & 0.060 \\
\hline No.2-11 & 49.7 & 51.9 & 64.2 & $<0.001$ & 0.001 & $<0.001$ \\
\hline No.2-12 & 78.4 & 78.4 & 104.5 & 0.001 & 0.025 & $<0.001$ \\
\hline No.2-13 & 150.2 & 150.4 & 177.9 & $<0.001$ & 0.015 & $<0.001$ \\
\hline No.2-14 & 118.6 & 118.2 & 148.4 & $<0.001$ & 0.001 & $<0.001$ \\
\hline No.2-15 & 64.5 & 64.5 & 64.5 & $<0.001$ & 0.031 & $<0.001$ \\
\hline No.2-16 & 47.1 & 47.8 & 53.4 & $<0.001$ & 0.015 & $<0.001$ \\
\hline No.3-11 & 13.3 & 13.3 & 13.3 & 0.015 & 0.734 & 0.031 \\
\hline No.3-12 & 21.0 & 21.0 & 26.3 & 0.018 & 0.308 & 0.036 \\
\hline No.3-13 & 37.2 & 37.4 & 43.5 & 0.171 & 1.906 & 0.156 \\
\hline No.3-14 & 37.5 & 37.8 & 46.7 & 0.011 & 0.578 & 0.008 \\
\hline No.3-15 & 28.3 & 28.1 & 33 & 0.009 & 0.325 & 0.013 \\
\hline No.3-16 & 22.5 & 23.0 & 29.6 & $<0.001$ & 0.059 & 0.015 \\
\hline No.4-11 & 8.6 & 8.8 & 37.4 & 0.001 & 0.106 & 0.001 \\
\hline No.4-12 & 20.0 & 23.1 & 40.8 & 0.253 & 2.328 & 0.234 \\
\hline No.4-13 & 49.0 & 52.3 & 72.1 & 0.109 & 2.031 & 0.359 \\
\hline No.4-14 & 47.7 & 51.2 & 82.2 & 0.003 & 0.629 & 0.006 \\
\hline No.4-15 & 11.97 & 12.06 & 36.58 & 0.019 & 0.484 & 0.026 \\
\hline No.4-16 & 2.92 & 3.08 & 8.1 & 0.031 & 0.921 & 0.045 \\
\hline
\end{tabular}

Table 5. Comparison II between PSO-NLTP, GA and EP with penalty strategy

As Table 4 and Table 5 indicate, PSO-NLTP performs the best of three in the items of average transportation cost and average computational cost. The NLTP solutions found by EP with penalty strategy cost more than PSO-NLTP and GA, which indicates recombination of PSO-NLTP and crossover of GA handle the constraints of NLTP (Exp. 4) better than the penalty strategy. However, EP with penalty strategy cost less time than GA to converge because the crossover and mutation operator of GA is more complicated. PSO-NLTP can cost the least to obtain the best NLTP solution of the three tested methods. Its recombination makes the particles feasible and evolutionary for optimization. The combination of updating rule and mutation operators can play a part of global searching quickly, which makes PSONLTP effective for solving NLTPs. 


\section{Discussions and Conclusions}

Most of the methods that solve linear transportation problems well cannot handle the nonlinear TP. An particle swarm optimization algorithm named PSO-NLTP is proposed in the present paper to deal with NLTP. The updating rule of PSO-NLTP can make the particles of the swarm optimally in the feasible solution space, which satisfies the constraints of NLTP. A mutation operator is added to strengthen the global optimal capacity of PSO-NLTP. In the experiment of computing 56 NLTP instances, PSO-NLTP performs much better than GA and EP with penalty strategy. All of the parameters of PSO-NLTP are set adaptively in the iteration so that it is good for the application of the proposed algorithm. Moreover, PSONLTP can also solve linear TPs.

The design of the updating rule of PSO can be considered as an example for solving optimization problems with special constraints. The operator is different from other methods such as stochastic approach, greedy decoders and repair mechanisms, which are to restrict the searching only to some feasible sub-space satisfying the constraints. It uses both the local and global heuristic information for searching in the whole feasible solution space. Furthermore, through the initial experimental result, it performs better than the penalty strategy which is another popular approach for handling constraints.

\section{References}

Papamanthou C., Paparrizos K., and Samaras N., Computational experience with exterior point algorithms for the transportation problem, Applied Mathematics and Computation, vol. 158, pp. 459-475, 2004. [1]

Vignaux G.A. and Michalewicz Z., A genetic algorithm for the linear transportation problem, IEEE Transactions on Systems, Man, and Cybernetics, vol. 21, no. 2, MARCWAPRIL, pp.445-452, 2004. [2]

Hitchcock F., The distribution of a product from several sources to numerous location, Journal of Mathematical Physics, vol. 20, pp. 224-230, 1941. [3]

Michalewicz Z., et al, A non-Standard Genetic Algorithm for the Nonlinear Transportation Problems, ORSA Journal on Computing, vol. 3, no. 4, pp.307-316, 1991. [4]

Li Y.Z., Ida K.C. and Gen M., Improved genetic algorithm for solving multi objective solid transportation problem with fuzzy numbers, Computers ind. Engng, vol. 33, no.3-4, pp. 589-592, 1997. [5]

Gen M., et al, Solving bicriteria solid transportation problem by genetic algorithms, Proceedings of the 16th International Conference on computers and industrial engineering, Ashikaga, Japan, pp.572-575, 1994. [6]

Dantzig G.B., Application of the simplex method to a transportation problem, in: T.C. Koopmans (Ed.), Activity of production and application, John Wiley \& Sons, NY, pp. 359-373, 1951. [7]

Orlin J.B., Plotkin S.A. and Tardos E., Polynomial dual network simplex algorithms, Math. Program, vol. 60, pp. 255-276, 1993. [8]

Paparrizos K., An exterior point simplex algorithm for general linear problems, Ann. Oper. Res., vol. 32, pp. 497-508, 1993. [9]

Papamanthou C., Paparrizos K. and Samaras N., Computational experience with exterior point algorithms for the transportation problem, Applied Mathematics and Computation, vol. 158, pp. 459-475, 2004. [10] 
Sharma R.R.K. and Sharma K.D., A new dual based procedure for the transportation problem, European Journal of Operational Research, vol. 122, pp. 611-624, 2000. [11]

Yang X. and Gen M., Evolution program for bicriteria transportation problem, Proceedings of the 16th International Conference on computers and industrial engineering, Ashikaga, Japan, pp. 451-454, 1994. [12]

Kennedy J. and Eberhart R.C., Particle swarm optimization, in Proc IEEE Int. Conf. Neural Networks, Perth, Austalia,pp. 1942-1948, Nov. 1995. [13]

Kennedy J., The particle swarm: Social adaptation knowledge, in Proc. 1997 Int. Conf. Evolutionary Computation, Indianapolis, IN, pp. 303-308, Apr. 1997. [14]

Fourie P.C. and Groenwold A.A., The particle swarm optimization algorithm in size and shape optimization, Struct Multidisc Optim, vol. 23, pp. 259-267, 2000. [15]

Shi Y.H. and Eberhart R.C., A modified particle swarm optimizer, Proc. Int. Conf. On Evolutionary Computation, pp.69-73, 1998. [16] 


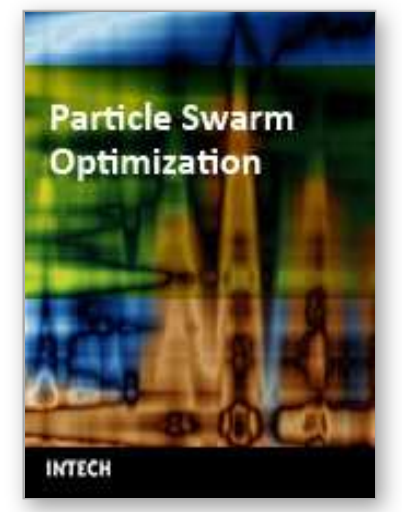

\author{
Particle Swarm Optimization \\ Edited by Aleksandar Lazinica
}

ISBN 978-953-7619-48-0

Hard cover, 476 pages

Publisher InTech

Published online 01, January, 2009

Published in print edition January, 2009

Particle swarm optimization (PSO) is a population based stochastic optimization technique influenced by the social behavior of bird flocking or fish schooling.PSO shares many similarities with evolutionary computation techniques such as Genetic Algorithms (GA). The system is initialized with a population of random solutions and searches for optima by updating generations. However, unlike GA, PSO has no evolution operators such as crossover and mutation. In PSO, the potential solutions, called particles, fly through the problem space by following the current optimum particles. This book represents the contributions of the top researchers in this field and will serve as a valuable tool for professionals in this interdisciplinary field.

\title{
How to reference
}

In order to correctly reference this scholarly work, feel free to copy and paste the following:

Han Huang and Zhifeng Hao (2009). Particle Swarm Optimization Algorithm for Transportation Problems, Particle Swarm Optimization, Aleksandar Lazinica (Ed.), ISBN: 978-953-7619-48-0, InTech, Available from: http://www.intechopen.com/books/particle_swarm_optimization/particle_swarm_optimization_algorithm_for_tra nsportation_problems

\section{INTECH}

open science | open minds

\section{InTech Europe}

University Campus STeP Ri

Slavka Krautzeka 83/A

51000 Rijeka, Croatia

Phone: +385 (51) 770447

Fax: +385 (51) 686166

www.intechopen.com

\section{InTech China}

Unit 405, Office Block, Hotel Equatorial Shanghai

No.65, Yan An Road (West), Shanghai, 200040, China

中国上海市延安西路65号上海国际贵都大饭店办公楼405单元

Phone: +86-21-62489820

Fax: +86-21-62489821 
(C) 2009 The Author(s). Licensee IntechOpen. This chapter is distributed under the terms of the Creative Commons Attribution-NonCommercialShareAlike-3.0 License, which permits use, distribution and reproduction for non-commercial purposes, provided the original is properly cited and derivative works building on this content are distributed under the same license. 